\title{
Accessory Penis and Scrotum in a Male Infant
}

\author{
Yi-Zheng Wang ${ }^{1}$ Li-Rong Cao ${ }^{1}$ Chun-Quan Cai ${ }^{2}$ \\ ${ }^{1}$ Graduate College of Tianjin Medical University, Tianjin, China \\ ${ }^{2}$ Department of Neurosurgery, Tianjin Children's Hospital, \\ Tianjin, China
}

J Child Sci 2017;7:e24-e26.

An 11-day-old infant was admitted to the hospital with an accessory penis and scrotum on the posterior thoracic region. He was a full-term vaginal delivery and there were no perinatal problems. His physical examination was unremarkable except for a midline, thoracic, soft tissue mass that measured $5 \times 4 \mathrm{~cm}$ and rose $1.5 \mathrm{~cm}$ above the plane of the back and an accessory small penis with well-formed glans, urethral meatus, and scrotum over the swelling. There were no formed testes ( - Fig. 1A, 1B). The ectopic phallus was firm and well defined but it became larger after tactile stimulation. Magnetic resonance imaging (MRI) of the spine revealed no evidence of the extension of the mass into the intraspinal space or defect of the vertebra but demonstrated a fusion of the spinous processes adjacent to the base of the mass ( - Fig. 2). Based on these features, a preoperative diagnosis of fetus in fetu (FIF) was made. The mass was excised. The resected specimen consisted of the "scrotal" structure with attached phallus and no testes were present. Pathological examination revealed abundant cavernous sinuses as well as smooth muscle cells present in the corpus cavernosum ( - Fig. $3 \mathbf{A}$ ) as in the primary penis; the
Address for correspondence Chun-Quan Cai, PhD, Department of Neurosurgery, Tianjin Children's Hospital, Beichen District, Tianjin 300134, China (e-mail: tjpns@126.com).

small cystic spaces lined by intestinal-type epithelium could be seen at the bottom of the penis near the scrotum (-Fig. 3B). The infant had an uneventful postoperative course and physical examination as well as neurologic examination. Both were within the normal limits. Clinical follow-up at 18 months did not show recurrence. The parents were fully informed and consent was obtained. All procedures performed in this study involving human participants were in accordance with the ethical standards of the institutional and/or national research committee and with the 1964 Helsinki declaration and its later amendments or comparable ethical standards.

The appearance of an ectopic genital organ is an extraordinarily rare event. Davis in 1949 reported a case of a peniform structure associated with a dermoid of the perineum. ${ }^{1}$ More recently, Baht et al described a gluteal pseudophallus in a male child. ${ }^{2}$ An accessory scrotum is also an unusual developmental anomaly with only 53 cases reported so far. ${ }^{3}$ Histological confirmation of penile and scrotum tissue is available in both published cases and our case. Hitherto, the correct classification of this rare deformity is not clear. Historically,

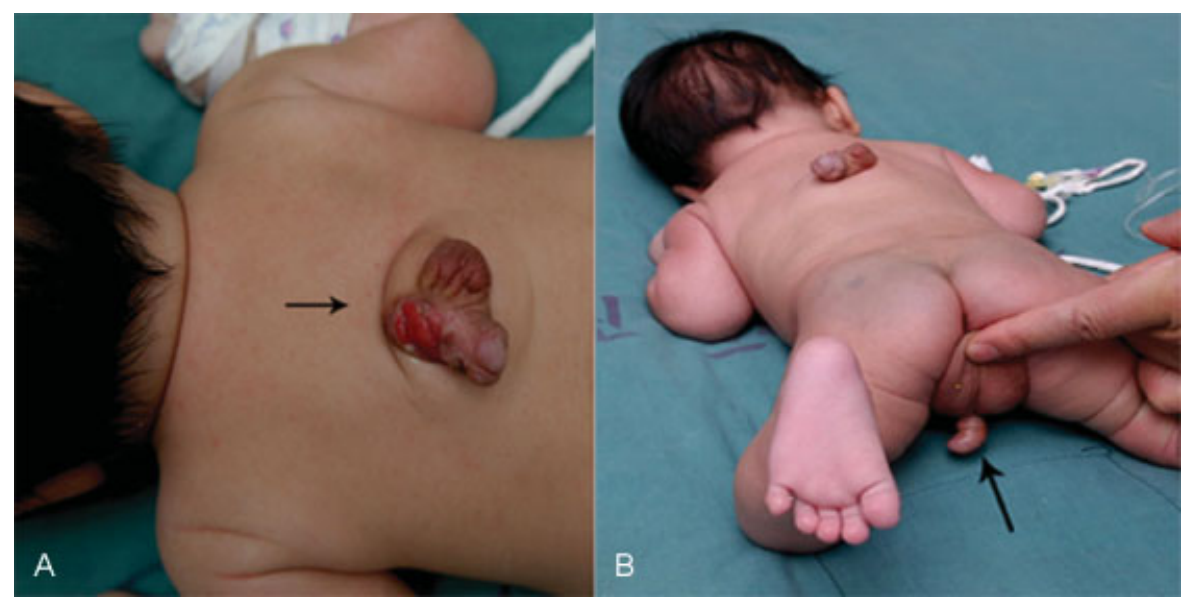

Fig. 1 (A) Accessory penis and scrotum on thoracic area over dorsal midline. (B) In the normal position is a penis of normal size and contour.

received

May 9, 2017

accepted after revision

June 1, 2017
DOI https://doi.org/

$10.1055 / \mathrm{s}-0037-1604158$.

ISSN 2474-5871.
Copyright @ 2017 Georg Thieme Verlag

KG Stuttgart · New York
License terms

(®) (1) $\Theta \circledast$ 


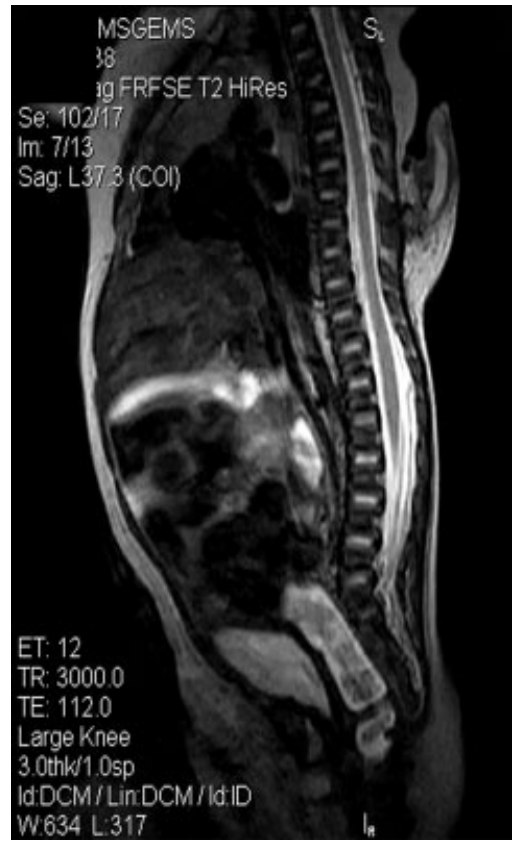

Fig. 2 Magnetic resonance imaging of the spine revealed no evidence of the extension of the mass into the intraspinal space or defect of the vertebra. differentiated teratoma. ${ }^{8}$ However, it is necessary to differentiate between FIF and teratoma because of a slight risk of malignancy associated with retroperitoneal teratomas. ${ }^{6-8}$ In contrast, FIF is almost always benign. ${ }^{6-8}$ In our case, the presence of intestinal-type epithelium found together with abundant cavernous sinuses and smooth muscles in the accessory penis implied that the accessory penis was nonsingle differentiation. This result validates the preoperative diagnosis of FIF. The recommended treatment for FIF is the complete surgical removal. As it is essentially a benign condition, FIF always has a good long-term prognosis. A regular follow-up should also be considered because one case of malignant recurrence after removal of FIF has been reported. ${ }^{9}$

\section{Acknowledgment \\ This study was funded by the Key Project of Tianjin Health Care Professionals (Grant no. 16KG166), the Science and Technology Foundation of the Tianjin Bureau of Public Health (Grant no. 2015KR12), the National Key Basic Research Program of China (973 Program) (Grant no. 2013CB945404) and the National Natural Science Foun- dation of China (Grant no. 81770612).}

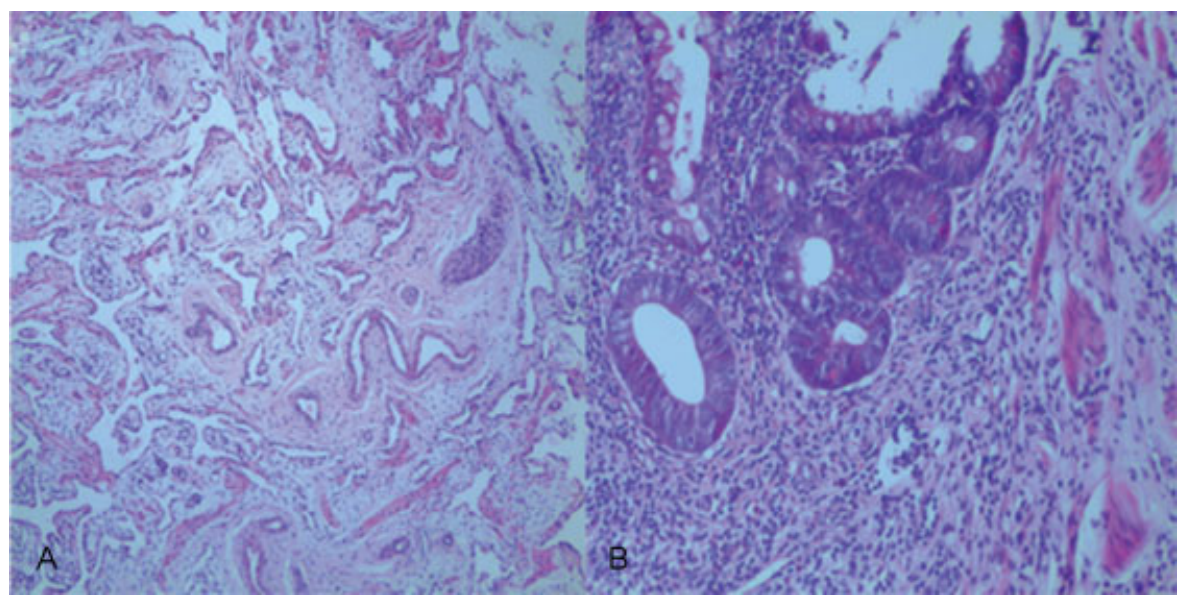

Fig. 3 (A) Abundant cavernous sinuses and smooth muscle cells showed in the corpus cavernosum of the accessory penis (hematoxylin-eosin, original magnification $\times 100$ ). (B) The small cystic spaces lined by intestinal-type epithelium surrounded by inflammatory cells at the root of the accessory near the scrotum (hematoxylin-eosin, original magnification $\times 100$ ).

authors have classified similar events as either FIF or teratoma. ${ }^{4,5} \mathrm{FIF}$ (also known as parasitic twins) is a rare congenital anomaly in which a vertebrate fetus is found inside a normal cotwin's body. ${ }^{6}$ The most widely accepted theory is that FIF results from the unequal division of the totipotent cells of a blastocyst. $^{6}$ The smaller twin then gets incorporated within the normally developing twin by unknown mechanisms. ${ }^{6}$ The most common site of FIF is the retroperitoneum. ${ }^{6,7}$ Unlike teratoma, which often occurs in the lower abdomen and pelvis, FIF generally occurs in the upper abdomen, and vertebral column and limbs often can be seen in these fetuses. ${ }^{7}$ Because some FIFs lack a spinal column as noticed in this case, investigators have suggested that FIF is a type of highly

\section{References}

1 Davis DM. A case of double, triple, or quadruple penis associated with dermoid of the perineum. J Urol 1949;61(01):111-115

2 Bhat AR, Raina TH, Arif S, et al. Gluteal pseudophallus in a male child: a rare cutaneous marker of occult spinal dysraphism. J Pediatr Neurosci 2009;4(02):127-130

3 Iida K, Mizuno K, Nishio H, et al. Accessory scrotum with perineal lipoma: pathologic evaluation including androgen receptor expression. Urol Case Rep 2014;2(06):191-193

4 Vaishya S, Pandey P. Unusual spinal teratoma with an accessory penis on the back. Childs Nerv Syst 2006;22(04):440-443

5 Kakizoe T, Tahara M. Fetus in fetu located in the scrotal sac of a newborn infant: a case report. J Urol 1972;107(03):506-508

6 Tiwari C, Shah H, KumbharV, Sandlas G, Jayaswal S. Fetus in fetu: two cases and literature review. Dev Period Med 2016;20(03):174-177 
7 Sitharama SA, Jindal B, Vuriti MK, Naredi BK, Krishnamurthy S, Subramania DB. Fetus in fetu: case report and brief review of literature on embryologic origin, clinical presentation, imaging and differential diagnosis. Pol J Radiol 2017;82: 46-49
8 Ji Y, Song B, Chen S, et al. Fetus in fetu in the scrotal sac: case report and literature review. Medicine (Baltimore) 2015;94(32):e1322 9 Hopkins KL, Dickson PK, Ball TI, Ricketts RR, O'Shea PA, Abramowsky CR. Fetus-in-fetu with malignant recurrence. J Pediatr Surg 1997;32(10):1476-1479 